\title{
Multicriteria Analysis to Determine Locations of Restaurant Branch Using Bayesian Network
}

\author{
Nilna Fauzia and Moses Laksono Singgih \\ Department of Management Technology, Institut Teknologi Sepuluh Nopember, Surabaya \\ e-mail: nilna.putrifauzia@gmail.com
}

\begin{abstract}
To determine a strategic restaurant location, a company has to consider several location criteria. Location criteria is divided into two perspective, namely customer perspective and management perspective. The purpose of the consideration of restaurant location criteria are to attract customer to come in so could obtain maximum profit for the unit business. Every restaurant has different location criteria, that is influenced by market segmentation of restaurant and business strategic of the company. The aim of this research is to learn about general restaurant location criteria, investigate specific restaurant location criteria, and do an assessment to obtain appropriate location alternative. Specific restaurant location of this research is location of Ayam Geprek "AG" Restaurant. This research use Bayesian Network Method to process probability of the criteria. This research obtain the data from questionnaire to management and potential customer Ayam Geprek "AG" Restaurant. The questionnaire consist of two steps, the first step is choices for Ayam Geprek "AG" criterion restaurant. The second questionnaire is about level of importance assessment every location criteria. There are three alternative location that will be rated based on the Ayam Geprek "AG" criteria. The result for the appropriate alternative is third alternative which are located in west Surabaya and has total score 18.11.
\end{abstract}

Keywords-Alternative, Bayesian Network, Criteria, Location.

\section{INTRODUCTION}

$\mathrm{R}$ ESTAURANT is one of the businesses that offers food and beverage services. Based on the latest data obtained from bps.go.id, the growth of the restaurant industry in East Java from 2013 to 2016 grew by $71 \%$. Based on research, there are several factors that influence consumer decisions to come and eat at certain restaurants. Some of these factors include the environment around the restaurant, cleanliness, speed of service, staff behavior, price, brand image, menu, quality, taste of cuisine, and location of the restaurant [1]. The location of the restaurant is one of the important factors that leads to the success of the restaurant because it is one of the pull factors and determines the convenience of the customer. In addition, location is also one of the significant factors to generate profit. Factors related to location such as location conditions, building type and structure, and the surrounding environment. Factors related to location are difficult to modify [2]. There are two main theories that can be applied to the location pattern of a restaurant. The first is Central Placed Theory, in this theory it is said that business units are not located uniformly, where there is high demand, then in that place the business will grow more diverse than locations with smaller demand [3]. The second is a special interaction theory which states there are three main factors

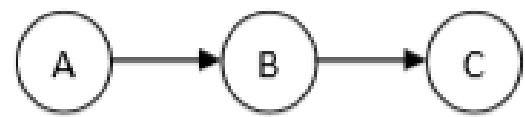

Figure 1. Serial Connection

that make up the business unit, namely demand, business attractiveness, and market accessibility [4]. The authors also stated that the results of visualization captured by geospatial mapping indicate that the distribution of fast food restaurants is in accordance with central place theory and special interaction theory. Good location is a location that considers geographical, demographic, and psychographic factors, and any change in these factors can have a significant influence on the attractiveness of the location [5]. The quality of location infrastructure must be compared and measured against key competitors to gain a sustainable competitive advantage and improve brand performance[6]. The location where the company does business is a major determinant of future success. For example, the strategic location of a restaurant and its ability to differentiate itself from its competitors to ensure long-term survival [5]. In a study, it was explained that the main characteristics of a good fast food restaurant location include, site accessibility, size, population in the area, level of competition, and economic conditions. [7]. Location selection has a positive effect on brand equity and is considered a dimension of brand equity [8]. From the literature review, it is also observed that the strategic location that is visible and located in an area that has a large population acts as one of the key indicators of a restaurant's success [9]. By looking at several multinational restaurants, they will choose the best place to operate their business based on population size and higher economic conditions. This strategy allows them to attract more customers and build a strong brand presence [1].

Restaurant location criteria are divided into 5 aspects, namely economy, transportation, competition, commercial area, and environment [10]. Hsiao \& Chen, divides location criteria into 4 aspects, namely regional characteristics, traffic, store conditions, the surrounding environment [2].

Bayesian Network is a classification algorithm that uses probability and statistics. Bayesian Network Theory has interdependence on the research variables. Bayesian Network is a method that uses conditional probability as the basis.

The Bayesian Network method is a good method in machine learning based on training data, using conditional probability as the basis. This method consists of 2 main parts, namely: directed Acyclic Graph (DAG) and Parameter Set.

The Bayesian Network graph structure is called the Directed Acyclic Graph (DAG), which is a directed graph 


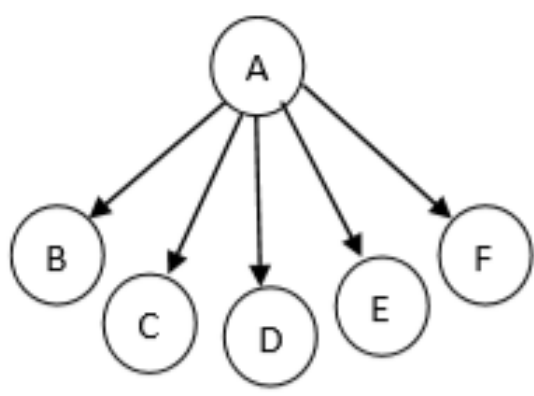

Figure 2. Divergent Connections

without a directed cycle. DAG consists of nodes and edges. Nodes represent random variables and edges represent the existence of direct dependency relationships and can also be interpreted as direct (cause-and-effect) effects between the variables they connect. The absence of an edge indicates a conditional freedom relationship between variables. This Bayesian Network graphic structure is used to represent knowledge about an uncertain domain. Specifically, each node in the graph is a random variable, while the ends between the nodes represent probabilistic that depend between the corresponding random variables. This dependency condition in the graph is often estimated using statistics known as computational methods. Therefore, the Bayesian Network combines the principles of graph theory, probability theory, computer science, and statistics.

Each node represents a variable / attribute. The parent node is a cause for child nodes. Nodes and edges are structural components in the Bayesian Network, while the probability at each node is a component of the Bayesian Network parameter. Bayesian Network makes decisions through probabilistic inference. Probabilistic inference is the decision making of an event based on an event that has occurred.

The parameter set defines the conditional probability distribution for each variable. On Bayesian Networks, nodes correspond to random variables. Each node is associated with a set of conditional opportunities, $\mathrm{p}(\mathrm{Xi} \mid \mathrm{Ai})$ so that $\mathrm{xi}$ is the variable associated with the node and $\mathrm{Ai}$ is the set of parents in the graph.

The equation of the Bayesian Network theorem is as follows

$P(C \mid X)=\frac{P(X \mid C) P(c)}{P(x)}$

Explanation:

$$
\begin{array}{ll}
\mathrm{X} & =\text { Characteristic clues for classification } \\
\mathrm{C} & =\text { data hypothesis } \\
\mathrm{P}(\mathrm{C} \mid \mathrm{X}) & =\text { the probability of a hypothesis based on the data } \\
& \text { it has (posterior) } \\
\mathrm{P}(\mathrm{C}) & =\text { hypothesis probability (likelihood) } \\
\mathrm{P}(\mathrm{X} \mid \mathrm{C}) & =\text { probability of the hypothesis condition (prior) } \\
\mathrm{P}(\mathrm{X}) & =\text { the probability c (evidence) }
\end{array}
$$

Opportunities for the entry of certain characteristics in samples in class $\mathrm{C}$ (posterior) are the opportunities for the emergence of class $\mathrm{C}$ multiplied by the opportunity for the appearance of the characteristics of class $\mathrm{C}$ samples, which divide the global opportunities for the emergence of sample characteristics. Therefore equation 1 can be written as follows

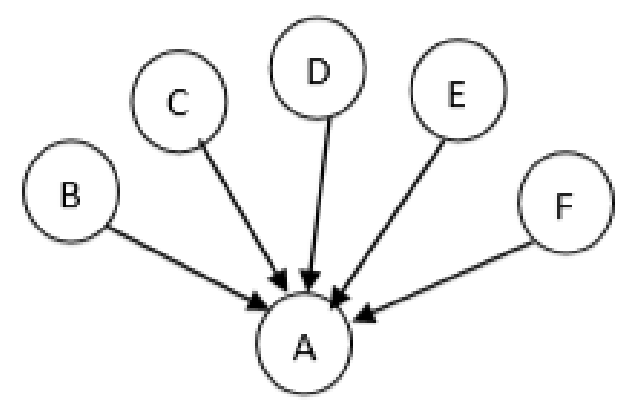

Figure 3. Convergent Connections

Posterior $=\frac{\text { prior } x \text { likelihood }}{\text { evidence }}$

Evidence remains of value in a class for each sample. The posterior value of a class will be compared with other classes to determine what class the sample is classified into.

Further elaboration on the Bayesian Network theorem is as follows

$$
\begin{aligned}
P(C \mid X 1, \ldots, X n)= & P(C) P(X 1, \ldots, X n \mid C) \\
& =P(C) P(X 1 \mid c)(X 2, \ldots, X n \mid C X 1)
\end{aligned}
$$

Bayesian Network in its structure is divided into three types of connections, namely serial, convergent, and divergent connections. The benefit of identifying this network topology is to find out the information dependency relationship between nodes on the Bayesian Network.

In Figure 1, shows the serial connection. In serial type connections, the probability value of node A variable will affect the probability of node $\mathrm{B}$ and the probability variable node $B$ will affect the probability of node $C$. This also applies vice versa, the probability of variable node $C$ will affect the probability of variable $B$ and the probability of variable $B$ will affect the probability variable A. However, when the value of $\mathrm{B}$ is known, the values of $\mathrm{A}$ and $\mathrm{C}$ become independent, or do not affect each other. This makes A and C separated when the value of $b$ is known.

Divergent connections as shown in Figure 2 information can flow on all existing paths from $A$ to each of its child nodes namely B, C, D, E and F if the value of A is unknown. But when the value of $\mathrm{A}$ is known then the paths that are in the child node $\mathrm{A}$ will be disconnected so that $\mathrm{B}, \mathrm{C}, \ldots, \mathrm{F}$ will become independent of each other. These conditions cause $\mathrm{B}$, $\mathrm{C}, \ldots, \mathrm{F} \mathrm{d}$-separated because the value of $\mathrm{A}$ is known.

Convergent Connections In structures with convergent connection types as illustrated in Figure 3, if no information is known at node $\mathrm{A}$, then the information between the parent nodes of A, namely B, C, .., F will be independent, so the values that are located the parent nodes will not affect the probability of other nodes. But when the value of A is known, the parent nodes will affect the other parent nodes [11].

The Bayesian Network theorem has several advantages and disadvantages. The strength of this theorem is that it only requires a small amount of data to determine the estimated parameters needed, perform calculations for quantitative and discrete data, requires little training data, to estimate parameters, and is efficient and fast. The weakness of the Bayesian Network theorem is that it cannot be used when the 
The $1^{\text {st }}$ International Conference on Business and Engineering Management (IConBEM)

February $1^{\text {st }} 2020$, Institut Teknologi Sepuluh Nopember, Surabaya, Indonesia

Table 1.

Ayam Geprek Restaurant "AG" Location Criteria Based On Customer Perspective

\begin{tabular}{|c|c|c|}
\hline $\begin{array}{c}\text { Consumer Criteria } \\
\text { Variable }\end{array}$ & Prior Probability & Probability \\
\hline \multirow[t]{3}{*}{ A1 } & Influential enough & 0.25 \\
\hline & Influential & 0.33 \\
\hline & Very influential & 0.42 \\
\hline \multirow[t]{2}{*}{ B1 } & Private motorcycle parking & 0.9 \\
\hline & $\begin{array}{l}\text { Online transportation motorcycle } \\
\text { parking }\end{array}$ & 0.1 \\
\hline \multirow[t]{3}{*}{$\mathrm{B} 2$} & The front is near the road & 0.26 \\
\hline & Not too close to the road & 0.54 \\
\hline & Away from the road & 0.20 \\
\hline \multirow[t]{3}{*}{ B3 } & Small & 0.14 \\
\hline & Medium & 0.50 \\
\hline & Large & 0.36 \\
\hline \multirow[t]{2}{*}{ B4 } & Low & 0.27 \\
\hline & High & 0.73 \\
\hline \multirow[t]{2}{*}{ B5 } & 1 Floor & 0.41 \\
\hline & 2 Floor & 0.59 \\
\hline \multirow[t]{2}{*}{$\mathrm{C} 1$} & Middle down & 0.8 \\
\hline & Middle up & 0.2 \\
\hline \multirow[t]{2}{*}{$\mathrm{C} 2$} & $15^{\text {th }}-24^{\text {th }}$ years old & 0.9 \\
\hline & $24^{\text {th }}-35^{\text {th }}$ years old & 0.1 \\
\hline \multirow[t]{3}{*}{ D1 } & Influential enough & 0.22 \\
\hline & Influential & 0.33 \\
\hline & Very influential & 0.45 \\
\hline \multirow[t]{3}{*}{ D2 } & Influential enough & 0.21 \\
\hline & Influential & 0.44 \\
\hline & Very influential & 0.35 \\
\hline
\end{tabular}

conditional probability is in zero and this theorem uses the assumption of the independent variable [11].

\section{METHODOLOGY}

\section{A. Data}

The type of data used in this study is primary data. Primary data obtained from the assessment of criteria factors carried out by customers and management through questionnaires. The customer referred to here is a potential customer from Ayam Geprek Restaurant "AG". Potential customers from the Ayam Geprek Restaurant "AG" are customers with junior high through college education. This potential customer is in line with the target market of the Ayam Geprek Restaurant "AG". The questionnaire for potential customers will be done by filling out the questionnaire online, so that the respondents obtained will be more varied so that the data obtained can be more valid. The management questionnaire was administered to the manager of the Ayam Geprek Restaurant "AG" which had direct involvement with the operational branch of the restaurant. The manager involved in filling out the
Table 2 .

Ayam Geprek Restaurant "AG” Location Criteria Based On Management Perspective

\begin{tabular}{|c|c|c|}
\hline $\begin{array}{c}\text { Management } \\
\text { Criteria Variable }\end{array}$ & Prior Probability & Probability \\
\hline \multirow[t]{2}{*}{ E1 } & Highway & 0.7 \\
\hline & Small road & 0.3 \\
\hline \multirow[t]{3}{*}{ E2 } & Low & 0.2 \\
\hline & Middle & 0.5 \\
\hline & High & 0.3 \\
\hline \multirow[t]{3}{*}{ E3 } & Not too important & 0.1 \\
\hline & Important & 0.4 \\
\hline & Very important & 0.5 \\
\hline \multirow[t]{3}{*}{$\mathrm{F} 1$} & Not too important & 0.2 \\
\hline & Important & 0.5 \\
\hline & Very important & 0.3 \\
\hline \multirow[t]{3}{*}{$\mathrm{F} 2$} & Educational Environment & 0.5 \\
\hline & Shopping center & 0.4 \\
\hline & Government Offices & 0.1 \\
\hline \multirow[t]{3}{*}{ F3 } & Not too important & 0.3 \\
\hline & Important & 0.2 \\
\hline & Very important & 0.5 \\
\hline \multirow[t]{3}{*}{$\mathrm{F} 4$} & Not too important & 0.2 \\
\hline & Important & 0.4 \\
\hline & Very important & 0.4 \\
\hline \multirow[t]{3}{*}{ G1 } & $\begin{array}{l}\text { There is a competitor in radius less than } \\
500 \mathrm{~m}\end{array}$ & 0.5 \\
\hline & $\begin{array}{l}\text { There is a competitor in radius } 500- \\
1 \mathrm{~km}\end{array}$ & 0.2 \\
\hline & $\begin{array}{l}\text { There is a competitor in radius more } \\
\text { than } 1 \mathrm{~km}\end{array}$ & 0.3 \\
\hline \multirow[t]{3}{*}{ G2 } & Not too important & 0.2 \\
\hline & Important & 0.2 \\
\hline & Very important & 0.6 \\
\hline \multirow[t]{3}{*}{ H1 } & Not too important & 0.2 \\
\hline & Important & 0.5 \\
\hline & Very important & 0.3 \\
\hline
\end{tabular}

questionnaire is the branch manager of the restaurant. Branch manager of the restaurant in this case is considered to have qualified knowledge of the condition of the location of the restaurant, the criteria that are an important consideration of a location, and expectations of future location conditions such as.

\section{B. Method}

Determination of the criteria factors is done by questionnaire. There are two types of questionnaires, namely the management questionnaire and the customer questionnaire. Determination of the criteria is done by distributing questionnaires to the management and restaurant customers. Determination of the criteria factors is the first stage questionnaire. At this stage, restaurant criteria based on management considerations will be judged based on " 1 " is Important "0" is not important. Rating "1" means the respondent considers that the proposed criteria are criteria that are considered to affect the location of the restaurant. 
Table 3 .

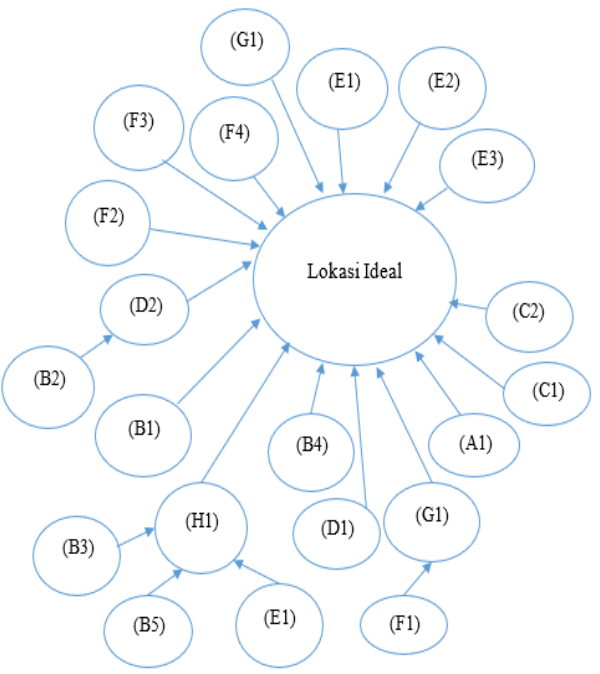

Figure 4. Structure of Bayesian Network

Criteria "0" is a criterion that is considered less influential on the location of restaurants. Whereas in the questionnaire for the customer the determination of the criteria is carried out together with the evaluation of the criteria.

The second stage questionnaire was used to obtain training data and test data. Training data is the result of questionnaire data conducted for a number of customers and management. The questionnaire for management is carried out by evaluating the importance of criteria that is considered by magagement. The customer questionnaire contains the criteria - criteria that the customer assesses from a restaurant location whether these criteria are important and how much influence or not important. While the test data is an assessment of the criteria for each alternative carried out by management when conducting a location survey. The assessment of these criteria is carried out as objectively as possible. In the training data, the questionnaire was carried out by giving a sign of the condition of the factors that felt the most appropriate and most influential in the choice of restaurant locations. A questionnaire for management was conducted to determine the level of urgency of each of the criteria factors for management. While the questionnaire for customers is done to find out what criteria most influence the location of a restaurant branch. Whereas on the test data, the questionnaire was used to assess the location of the restaurant based on the actual variable state of the alternative.

Data processing is performed on training data. Data processing is done by calculating the probability of each variable criteria chosen by the customer and management. In the data processing stage, a Directed Acyclic Graf (DAG) structure is formed. The formation of DAG structure is done by dependency analysis. Namely by looking for a qualitative relationship of each criterion variable. The qualitative relationship between these criteria was obtained from the study of various literatures and viewed from various aspects. For example, the variable criteria for the price of renting a restaurant with the size of a building has a causal relationship or not. If you have a causal relationship, the probabilities of the rental price of a location will affect each other on the probability of the building area. Therefore, the formation of DAG structure will also be done qualitative analysis to look
The Meaning of Values For Each Criteria.

\begin{tabular}{|c|c|c|c|}
\hline \multirow{2}{*}{ Criteria } & \multicolumn{3}{|c|}{ Score } \\
\hline & 1 & 2 & 3 \\
\hline A1 & A little & enough & Many \\
\hline B1 & Narrow & Wide & - \\
\hline B2 & Near the road & Middle & Far from the road \\
\hline B3 & Narrow & Medium & Wide \\
\hline B4 & Low & High & - \\
\hline B5 & 1 Floor & 2 Floors & - \\
\hline $\mathrm{C} 1$ & Low & High & - \\
\hline D1 & Difficult & Medium & Easy \\
\hline D2 & High & Medium & Low \\
\hline E1 & Environmental road & Highway & - \\
\hline E2 & Low & Medium & High \\
\hline E3 & Low & Medium & High \\
\hline $\mathrm{F} 1$ & $>1 \mathrm{~km}$ & $500 \mathrm{~m}-1 \mathrm{~km}$ & $<500 \mathrm{~m}$ \\
\hline $\mathrm{F} 2$ & Office & Mall & Education \\
\hline $\mathrm{F} 3$ & Difficult & Medium & Easy \\
\hline $\mathrm{F} 4$ & Difficult & Medium & Easy \\
\hline G1 & $<500 \mathrm{~m}$ & $500 \mathrm{~m}-1 \mathrm{~km}$ & $>1 \mathrm{~km}$ \\
\hline $\mathrm{G} 2$ & Low & Medium & High \\
\hline $\mathrm{H} 1$ & Cheap & Medium & Expensive \\
\hline
\end{tabular}

for relationships between two variables that have the possibility of the formation of relationships between variables, where one variable affects the other variables. Weighting of criteria is carried out with several stages, i.e

1. The first step is parameter estimation. Parameter estimation is to calculate the prior probability of each node. Prior probability is the probability of trusting something if nothing else is known. This prior probability is the initial probability that is known based on the results of the questionnaire before further calculations.

2. The second stage is calculating Conditional Probability. Conditional Probability is the probability of the occurrence of variable B if variable A has occurred. Conditional Probability is a variable probability obtained after conducting a dependency analysis of one variable with another variable.

3. The last stage is to form a model with Bayes Server software. In forming this model, the value of Joint Probability Distribution will be seen. Joint Probability Distribution is the probability of joint emergence of a combination of the values of variables $\mathrm{A}$ and $\mathrm{B}$, or it can be said what is the probability of occurrence of the values of variables A and B if the two variables affect each other and have the probability of occurrence of each.

After the model is formed, the probability of each criterion variable will be met. Model interpretation phase is the last step in data processing. At this stage an assessment of the joint probability distribution is carried out, namely the assessment of each alternative restaurant that is affected by the weight of each criterion.

To determine the alternative decision for the location of the restaurant, the value of each alternative is calculated. From each alternative a priority decision is then obtained based on the alternative weight which has the highest posterior value. 
The $1^{\text {st }}$ International Conference on Business and Engineering Management (IConBEM)

February $1^{\text {st }} 2020$, Institut Teknologi Sepuluh Nopember, Surabaya, Indonesia

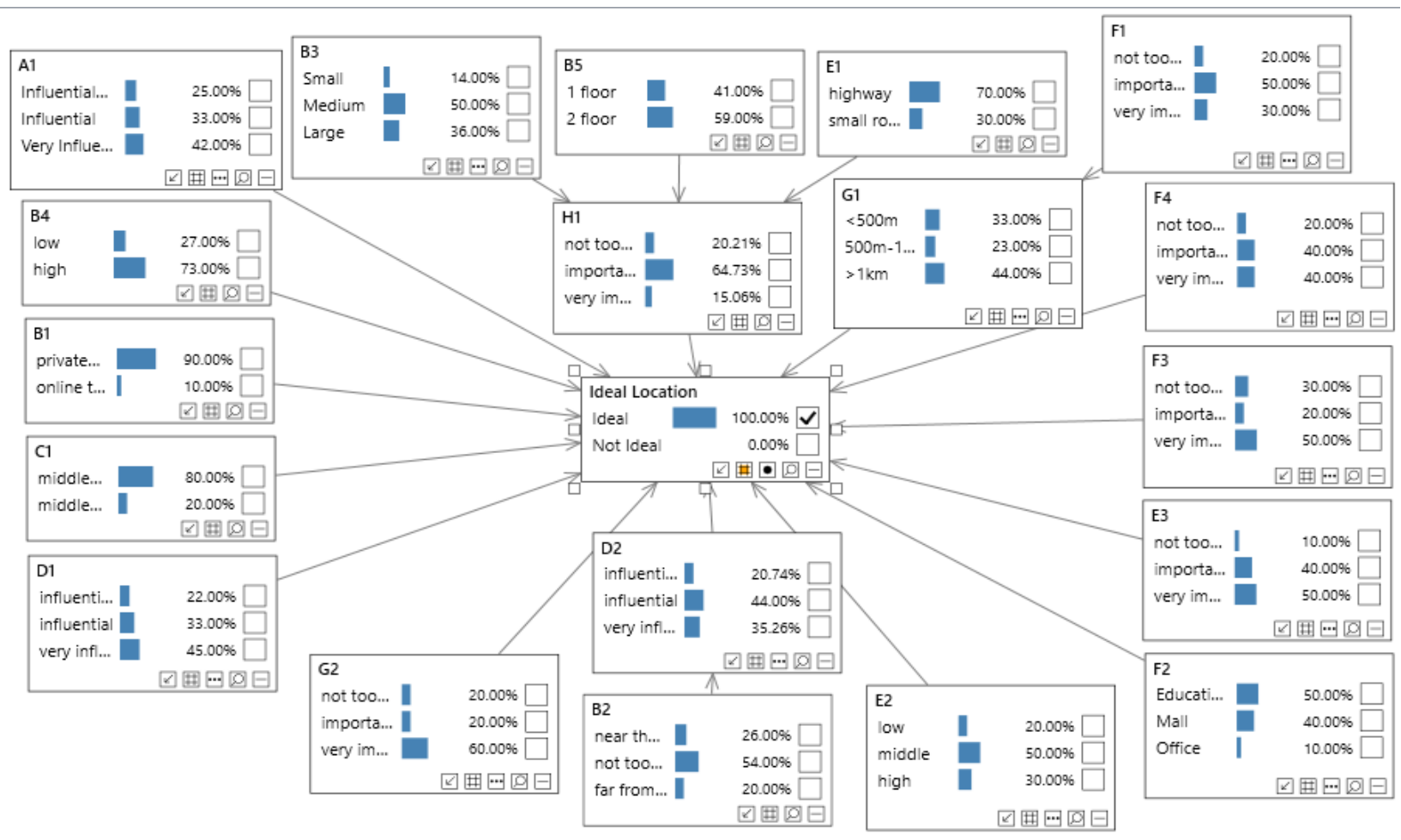

Figure 5. Construct Model of Bayesian Network by Set Evidence 100\%

The highest posterior is the probability that the alternative has the criteria closest to the criteria expected by the customer and management.

At the stage of data analysis and discussion, an analysis of general criteria must be known by a prospective restaurant location. This general analysis is not only a criterion that must be owned by the Ayam Geprek Restaurant "AG" but, criteria that can be a general consideration of various types of restaurants. Furthermore, in this study further analysis will be conducted regarding the location criteria that must be owned by an Ayam Geprek Restaurant "AG". Analysis of the criteria that must be owned by the Ayam Geprek Restaurant "AG" was obtained from the first stage questionnaire where respondents both from customer respondents and management respondents as much as $95 \%$ of respondents said that these criteria were influential or important criteria. Then, in the second questionnaire, we will see the weighting of each variable to influence the choice of restaurant locations. At this stage, the posterior probability of each alternative is known. Posterior probability is calculated from the joint probability distribution to see whether or not the probability of each alternative.

\section{RESULT AND DISCUSSION}

This research was conducted by giving a questionnaire to potential customers of the Ayam Geprek Restaurant "AG" where the total respondents were 100 people. From the results of the questionnaire, potential customers of the Ayam Geprek Restaurant "AG" are aged 22 years (25\%), 23 years (34\%), and 24 years $(27) \%$. There are also potential customers aged 18 to 21 years, aged 25 years to 29 years, no more than $5 \%$. The average distribution of the largest customer work is as employees, students, and followed by fresh graduates. As for other types of work, but not so many are as teaching staff, freelancers, and housewife. Employees are 40\% and students are $35 \%$ then fresh graduates are $12 \%$. Teaching staff is $4 \%$, freelancers $5 \%$, and housewife $5 \%$. The percentage of sex is $24 \%$ male and $76 \%$ female.

Based on the results of the questionnaire, the factors that attract customers of the Ayam Geprek restaurant "AG" are divided into 9 criterion variables, namely green environment (A1), parking conditions (B1), building position (B2), building area (B3), building height (B4), number of building floors (B5), income (C1), age (C2), easy access to location (D1), and noise level (D2). To facilitate writing, in the future each of these criterion variables will be replaced with a specific code. The purpose of this replacement is so that the writing is shorter but does not change the meaning of the criterion variable. The new writing can be seen in the code after the name of the criterion variable.

The questionnaire to the management of the Ayam Geprek Restaurant "AG" was given to the central management and each head of the branch shop of the Ayam Geprek Restaurant "AG". This questionnaire was given to 10 respondents consisting of 4 central management and 6 shop heads. The criterion variables considered by management are as follows: road in front of the location (E1), pedestrian volume (E2), regional development (E3), distance from public facilities (F1), the existence of certain public facilities (F2), ease of access supply (F3), ease of waste disposal (F4), presence of competitors $(\mathrm{G} 1)$, competitor intensity $(\mathrm{G} 2)$, building rental price $(\mathrm{H} 1)$.

\section{Formation of Bayesian Network Structures}

The formation of the Bayesian Network structure is done by compiling the Directed Acyclic Graph (DAG) by means of qualitative analysis based on previous research and literature studies. In the formation of this Bayesian Network 
The $1^{\text {st }}$ International Conference on Business and Engineering Management (IConBEM)

February $1^{\text {st }} 2020$, Institut Teknologi Sepuluh Nopember, Surabaya, Indonesia

Table 4.

Calculation of The Total Value of Each Alternative.

\begin{tabular}{ccccccc}
\hline & \multicolumn{6}{c}{ The value of each alternative } \\
\cline { 2 - 7 } Criteria & \multicolumn{2}{c}{ Alternative 1 } & \multicolumn{2}{c}{ Alternative 2 } & Alternative 3 \\
\cline { 2 - 7 } & Score & Weight & Score & Weight & Score & Weight \\
\hline A1 & 2 & 0,33 & 2 & 0,33 & 3 & 0,42 \\
B1 & 2 & 0,9 & 2 & 0,9 & 2 & 0,9 \\
B3 & 2 & 0,54 & 2 & 0,54 & 2 & 0,54 \\
B4 & 2 & 0,5 & 2 & 0,5 & 3 & 0,36 \\
B5 & 2 & 0,73 & 1 & 0,27 & 2 & 0,73 \\
C1 & 1 & 0,41 & 2 & 0,59 & 1 & 0,41 \\
D1 & 2 & 0,8 & 1 & 0,2 & 2 & 0,8 \\
D2 & 1 & 0,45 & 1 & 0,33 & 3 & 0,22 \\
E1 & 2 & 0,27 & 1 & 0,44 & 2 & 0,35 \\
E2 & 1 & 0,2 & 1 & 0,2 & 2 & 0,5 \\
E3 & 3 & 0,5 & 1 & 0,1 & 3 & 0,4 \\
F1 & 3 & 0,3 & 3 & 0.3 & 2 & 0,5 \\
F2 & 1 & 0,5 & 1 & 0,5 & 1 & 0,5 \\
F3 & 3 & 0,3 & 2 & 0,4 & 3 & 0,3 \\
F4 & 1 & 0,2 & 2 & 0,4 & 3 & 0,4 \\
G1 & 1 & 0,33 & 2 & 0,23 & 2 & 0,23 \\
G2 & 2 & 0,2 & 3 & 0,6 & 1 & 0,2 \\
H1 & 1 & 0,2 & 1 & 0,2 & 1 & 0,2 \\
\hline \hline & & 16,16 & & 13,02 & & 18,11 \\
\hline
\end{tabular}

structure, each node in which there is a criterion variable will be correlated and connected by an arc (arrow). However, this correlation still ignores the strong correlation between weak nodes.

Green environment, income, age, and type of transportation are 4 factors that influence the selection of the ideal location of a restaurant based on customer consideration. In Figure 4.4 the first correlation can be seen namely green environment, income, age, and type of transportation have an influence on the ideal location. Green environment influences the choice of an ideal location because the more green plants around the building, the greater the amount of oxygen released, especially during the daytime. The amount of oxygen that is in a location will affect the coolness and comfort of a person when in that location, especially in areas that have high air temperatures during the day. So that more or less green environment affects customers to visit a location.

Customer income affects the choice of the location of a restaurant because it is related to market segmentation of restaurants. Ayam Geprek Restaurant "AG" has a middleincome customer market segmentation such as employees, students and upper level students. Employees, students, and high-level students will be interested in the Ayam Geprek Restaurant "AG" not only because of its strategic location, but also the price offered according to their daily budget.

A person's age influences food tastes so it affects the choice of restaurants to be visited. Potential customers for Ayam
Geprek Restaurants "AG" are productive age communities where at this age customers tend to behave like challenges. Ayam Geprek Restaurant "AG" offers a unique food menu that has spicy levels ranging from the lowest to the highest and the portion of rice and vegetables that can be taken as much so that it becomes a special attraction for customers. Therefore, these productive-aged customers have an interest in unusual menus and offerings and get food satisfaction on an affordable budget. So, they will decide to choose Ayam Geprek Restaurant "AG" where the location is reachable by the customer.

The position of the restaurant building from the road will affect the size of the possibility can be seen by road users. However, on the other hand it will affect the noise level of the highway in the building. If the position of the building is very close to the highway, it is likely that the noise level will be high. However, if far from the highway, the noise level is most likely low. Therefore, the position of the building will affect the noise level at a location and this noise level will affect the convenience of customers at that location, thereby affecting the customer's decision to visit that location.

The choice of location near public facilities where demand in the region is high also affects the intensity of competitors in the area. The choice of location where there are many demands is in accordance with Central Placed Theory where this theory says that where there is demand in an area, business units will grow and develop in the region.

Factors that become management considerations when choosing a location for restaurants include pedestrian volumes, regional developments, regional regulations, the existence of public facilities, ease of supply of raw materials, ease of waste disposal, and competitive intensity.

The volume of pedestrians has an effect that cannot be ignored when choosing a location to make a restaurant business. This is because it will have a direct effect on needs. It is undeniable that when walking power will run out and sweat will come out. Thus, the existence of a restaurant becomes very strategic in locations where the volume of pedestrians in the area is very high. This can be explained that in areas that have high pedestrian volumes, restaurants have the opportunity to sell their products to pedestrians so that pedestrian volume factors influence restaurant selection decisions.

The development of the region is of particular concern in determining the location of restaurants. In areas that have high growth and development, it will automatically increase the people's income in the area, with the increase in income, the ability or purchasing power of the children's community to rise. So, it can be concluded that the development of the region influences the decision of the location selection of a restaurant

Regional regulations on a business in certain areas will affect the decision of business people to run their business. When a regulation is supportive of business actors, then the business owner will feel benefited by the regulation, but when the regulation is considered burdensome, then the business owner will feel disadvantaged by the regulation. In the restaurant business where the location of the restaurant is located, will also comply with local regulations in the region. 
The $1^{\text {st }}$ International Conference on Business and Engineering Management (IConBEM)

February $1^{\text {st }} 2020$, Institut Teknologi Sepuluh Nopember, Surabaya, Indonesia

So it can be concluded that local regulations will affect the choice of restaurant locations.

The existence of certain public facilities will greatly affect the location of a restaurant. Regions that have public facilities have high demand. The Ayam Geprek Restaurant "AG" has a market segmentation of students, employees, and upper level students. Thus, the existence of public facilities such as malls, campuses, and schools greatly influence the management decision of Ayam Geprek Restaurant "AG" to determine the location of the restaurant.

The level of ease of supply of raw materials is an important factor to consider. Because this will be related to costs. A restaurant location which is far from the source of raw materials will cause high transportation costs. This will make production costs go up. With prices that have been set the same between one location with another location, causing a reduced profit margin at that location. So the ease of supply of raw materials is a factor that needs to be considered when choosing the location of the Ayam Geprek Restaurant "AG".

In the restaurant industry, waste is always a problem. Restaurant waste is waste that cannot be stored for a long time because it will interfere with clean air circulation. The waste of the restaurant must be routinely cleaned so as not to disrupt the operation of the restaurant. Certain locations have good waste disposal systems, but some are not. Therefore, ease of waste disposal affects the choice of restaurant locations.

The intensity of competitors is the level of ability or strength of competitors in managing food business. The intensity of competitors is a concern when choosing a location for a restaurant business. High intensity competitors such as high sales will always be visited by buyers. This will affect the restaurant brand equity. This can make people judge that competitors are far superior, thereby reducing the level of public confidence in business. The opposite is true if the intensity of competitors is lower than the restaurant brand. This will make it look as if our brand is seen better by the community and increase the level of public trust in the restaurant brand. Therefore, the intensity of these competitors influences the choice of restaurant locations.

Criteria factors that affect rental price an Ayam Geprek Restaurant "AG" location include building area, number of floors, road in front of the location.

Two-story building certainly has a more expensive rental price than a building that has one floor. However, a two-story building is not necessarily not an option, although rents are more expensive, however, if it can bring in more customers than it might become more profitable.

The road in front of the restaurant location gives a clue about the market segmentation of the restaurant. If the road is on a road that connects two cities or two provinces, usually the market segmentation is the trucks that distribute goods. However, if the road in front of the location is a highway, usually the market segmentation is the workers or students around the road. If the location is on a residential road, then the market segmentation is the residential residents. The more crowded the road in front of the location, the more available market segmentation, the more expensive the building rental price. Each variable node has been successfully connected with arc. If combined, it will be shown in Figure 4 about the structure of the Bayesian Network ideal location based on the variable criteria that influence.

\section{Model Formation}

The stage of forming the model is the stage to see the probability of occurrence with each of the variables that influence the determination of the location of the Ayam Geprek Restaurant "AG". This model is considered 100\% ideal which in the future will be used to determine the value of each alternative location of the Ayam Geprek Restaurant "AG".

Figure 5 is a Bayesian Network construct model with an ideal evidence set of $100 \%$. Where the probability of each criterion and their interrelation with the probability of other criteria forms an ideal model of $100 \%$. Each weight value in this model will be used to calculate the value of each alternative location.

\section{Alternativ e Assessments}

Alternative assessment phase is done by calculating the total alternative (posterior) value of each location. To calculate the total alternative value (posterior) the Bayes equation is used as follows

$T i=\sum \mathrm{H} i j \times \mathrm{M} j$

Explanation:

$T i \quad$ : the total final value of alternative $\mathrm{i}$

$\mathrm{Hij}$ : the value of the $\mathrm{i}$-alternative on the $\mathrm{jth}$ criterion

$\mathrm{M} j \quad$ : importance level (weight) jth criteria

i $\quad: 1,2,3, \ldots, n ; n=$ many alternatives

j $\quad: 1,2,3, \ldots, m ; m=$ many criteria

Criteria number one through number nine is a criterion which is the customer rating of the location of a restaurant. Whereas criteria number ten to 19 are criteria that management considers in determining restaurant locations.

In the calculations shown in Table 4, the meaning of each number in the value column can be seen in Table 3 .

While the weight is the weight or influence of the condition of the location criteria to form an ideal location. The weights of each of the criteria used in the calculations in Table 4 are obtained from the ideal location model with $100 \%$ Evidence Set in Figure 5.

From the results of the calculations in Table 4.10, it can be seen that the best alternative decision to determine the location of a Ayam Geprek Restaurant "AG"in a row is location three, location one, and location two with each posterior value of each location is location three by 18,11 ; location one is 16.16; and location one is 13.02

\section{CONCLUTION}

Criteria variables that are considered for the selection of the location of the Ayam Geprek Restaurant "AG" can be grouped based on two considerations, namely consumer considerations and management considerations. Criteria variables that are considered by consumers are green environment (A1), parking conditions (B1), building position (B2), building area (B3), building height (B4), number of building floors (B5), income $(\mathrm{C} 1)$, age $(\mathrm{C} 2)$, easy access to locations (D1), and noise levels (D2). The criterion variables considered by management are as follows: road in front of the 
The $1^{\text {st }}$ International Conference on Business and Engineering Management (IConBEM)

February $1^{\text {st }} 2020$, Institut Teknologi Sepuluh Nopember, Surabaya, Indonesia

location (E1), pedestrian volume (E2), regional development (E3), distance from public facilities (F1), the existence of certain public facilities (F2), ease of access supply (F3), ease of waste disposal (F4), presence of competitors (G1), competitor intensity (G2), building rental price (H1).

Case studies have been conducted to determine the best alternative choice of several prospective restaurant locations by considering the importance of each of the criterion variables using the Bayesian Network method. There are three alternative locations that will be assessed based on criteria weights. The results showed the best alternative to be chosen as the location of restaurants is alternative three, located in the West Surabaya area with a total score of 18.11

\section{REFERENCES}

[1] J. Hanaysha, "Restaurant Location and Price Fairness as Key Determinants of Brand Equity: A Study on Fast Food Restaurant Industry," Bus. Econ. Res., vol. 6, no. 1, p. 310, 2016.

[2] Y.H. Hsiao and G. T. Chen, "Customer Kansei-oriented restaurant location evaluation using Kansei Engineering," 2018 5th Int. Conf. Ind. Eng. Appl. ICIEA 2018, pp. 299-303, 2018.
[3] R. A. Litz and G. Rajaguru, "Does Small Store Location Matter? A Test of Three Classic Theories of Retail Location," J. Small Bus. Entrep., vol. 21, no. 4, pp. 477-492, 2008.

[4] T. Nakaya, S. A. Fotheringham, K. Hanaoka, G. Clarke, D. Ballas, and $\mathrm{K}$. Yano, "Combining microsimulation and spatial interaction models for retail location analysis," J. Geogr. Syst., vol. 9, no. 4, pp. 345-369, 2007.

[5] H. G. Parsa, J. T. Self, D. Njite, and T. King, "Why restaurants fail," Cornell Hotel Restaur. Adm. Q., vol. 46, no. 3, pp. 304-322, 2005.

[6] D. Melia, "Critical Success Factors and Performance Management and Measurement: A Hospitality Context," p. 19, 2011.

[7]@ @r Harold and G. Love, "Fast Food Store Location Factors: A Comparison with Grocery Store Location Factors," 1972.

[8] N. T. N. Wang, Lai Wang, Thanh Tuyen Tran, "Analyzing Factors To Improve Quality Of Local Specialties Restaurants: A Comparison With Fast Food Restaurants In Southern Vietnam," vol. 4, no. 11, pp. 1592-1606, 2014.

[9] M. Al-Jumaily, K. Roos, S. Bessaguet, and M. Jo Avila, "Prestretched airway smooth muscle response to length oscillation," Physiol. Rep., vol. 5, no. 2, pp. 1003-1013, 2017.

[10] G. H. Tzeng, M. H. Teng, J. J. Chen, and S. Opricovic, "Multicriteria selection for a restaurant location in Taipei," Int. $J$. Hosp. Manag., vol. 21, no. 2, pp. 171-187, 2002.

[11] W. Zhang and F. Gao, "An improvement to naive bayes for text classification," Procedia Eng., vol. 15, pp. 2160-2164, 2011. 